Sara Faramarzi ${ }^{1}$, Younes Anzabi ${ }^{2,3}$ and Hoda Jafarizadeh-Malmiri, ${ }^{4, *}$

\title{
Selenium supplementation during fermentation with sugar beet molasses and Saccharomyces cerevisiae to increase bioethanol production
}

https://doi.org/10.1515/gps-2019-0032

Received October 27, 2018; accepted April 29, 2019.

Abstract: A bench scale submerged fermentation process was used to bioethanol produce using sugar beet molasses and Saccharomyces cerevisiae, as substrate and microbial strain, respectively. Effects of selenium amount on growth of $S$. cerevisiae and bioethanol production were evaluated. The obtained results indicated that growth of $S$. cerevisiae (manifested as turbidity intensity) in the samples containing $0,5,10,15,20$ and $25 \mu \mathrm{g}$ sodium selenite, during aerobic process, was $0.1707,0.1678,0.1679,0.1664,0.1627$ and $0.160 \%$ a.u./h (after $14 \mathrm{~h}$ incubation), respectively. Statistical analysis based on compression test indicated that there were insignificant $(p>0.05)$ differences between growth rate of the yeast in the fermented samples containing S. cerevisiae and 5 to $25 \mu \mathrm{g}$ selenium salt. Response surface methodology was utilized to evaluate effects of two fermentation parameters namely, amount of selenium $(5-25 \mu \mathrm{g})$ and substrate brix $\left(10-25^{\circ} \mathrm{Bx}\right)$ on the concentration $(\mathrm{g} / \mathrm{L})$ of produced bioethanol. Obtained results revealed that maximum bioethanol concentration $(55 \mathrm{~g} / \mathrm{L})$ was achieved using $15 \mu \mathrm{g}$ selenium and molasses with $25^{\circ} \mathrm{Bx}$. Furthermore, results have also indicated that, without using selenium and using molasses with $25^{\circ} \mathrm{Bx}$, bioethanol with concentration of $29 \mathrm{~g} / \mathrm{L}$ was produced.

Keywords: bioethanol overproduction; Saccharomyces cerevisiae; selenium; substrate brix; optical density

\footnotetext{
* Corresponding author: Hoda Jafarizadeh-Malmiri, Hoda Jafarizadeh-Malmiri, Faculty of Chemical Engineering, Sahand University of Technology, East Azarbaijan, Tabriz, Iran.

Tel: +98 4133459099, Fax: +98413-3444355,

e-mail: h_jafarizadeh@sut.ac.ir; h_jafarizadeh@yahoo.com Sara Faramarzi, Department of Microbiology, Faculty of Basic Science, Tabriz Branch, Islamic Azad University, Tabriz, Iran Younes Anzabi, Department of Pathobiology, Tabriz Branch, Islamic Azad University, Tabriz, Iran, Biotechnology Research Center, Tabriz Branch, Islamic Azad University, Tabriz, Iran
}

\section{Introduction}

Food wastes contain main carbohydrates such as pectic, starchy and sugary compounds which those are accumulated every year and caused ecological problems. Incorporation of biotechnology methods and approaches into chemical and environmental engineering aspects, is of great interest to overcome the environmentally concerns resulted by the wastes. Recently, food and agro-wastes have gained more attention to be utilized in biotechnologically processes as an enriched and suitable substrate to produce valuable products such as food additives, enzymes, antibiotics, organic acids, biofuel and biogas [1].

Bioethanol is known as clean, cost-effective and ecofriendly fuel and has been widely utilized in developed countries as alternative and replacement of the fossil fuels [2,3]. In fact, bioethanol can also be used as gasoline improver or octane enhancer to increase flames speed and heats of vaporization with minimum toxicity and airborne pollutants [4]. Therefore, its production through submerged fermentation and using agro-industrial by-products, especially sugar beet molasses, is an attractive and eco-friendly topic these days.

Several studies have been indicated that the yield of bioethanol production through fermentation, influences by numerous parameters such as type and volume of inoculum (microorganisms strain), composition and concentration of substrate (growth media), $\mathrm{pH}$, temperature, osmotic pressure of the culture media, and presence of nutrients, minerals and precursors [5,6]. Selenium as an essential trace element has crucial role in animal lives, human health and micro/macro flora. But, due to its low concentration in vegetables (as human diets) and its short bioavailability, many people are poor because of this vital element $[7,8]$. Conversion of selenium to organic selenium compounds such as seleno-proteins (especially seleno-methionine and seleno-cysteine) and seleno-enzymes, improves selenium deficiency in the human body and shows numerous biological activities such as antioxidant and anti-inflammatory activities 
$[8,9]$. Several studies indicated that yeast cells are capable to absorb selenium and bio-transform it into seleno-methionine and seleno-cysteine [10-13]. Seleniumenriched yeasts, which are known as selenised yeasts, are the base of many consumed supplements and most popular. For examples, enriched yeasts with selenium, such as Saccharomyces cerevisiae, S. bayanus and $S$. boulardii have been utilized to produce bread, probiotic products and alcoholic beverages [12,14,15]. Several studies indicated that, glutamate in the yeast, can decrease the energy generation and fermentation rate, by altering the mitochondrial structure and dynamics, which those negatively impacts can be prevented by organic selenium such as seleno-cysteine which that is resulted during bio-transformation of inorganic selenium using yeasts such as $S$. cerevisiae $[12,14]$. Other study indicated that contents of organic selenium in the $S$. cerevisiae during fermentation process to produce bioethanol, increased with the increase in selenium concentration up to $2 \mu \mathrm{g} / \mathrm{mL}$ followed by a gradual decrease after $24 \mathrm{~h}$ of incubation. It reveals that organic selenium has low bioavailability [16]. Furthermore, some species of Saccharomyces, such as Yarrowia lipolytica, has selenium tolerance and selenium in lower amounts, cannot significantly inhibit its growth [15]. To the best of our knowledge, there is not any comprehensive study to evaluate effects of selenium salt and culture media concentrations on production of bioethanol through submerged fermentation process using $S$. cerevisiae and sugar beet molasses. Furthermore, the mechanism of the selenium on production of bioethanol using $S$. cerevisiae is unknown.

Therefore, the main objectives of the present study were to i) evaluate the effect of selenium on the concentration of produced bioethanol, ii) optimize submerged fermentation parameters namely substrate and selenium concentrations to achieve bioethanol with highest concentration, and iii) compare concentration of produced bioethanol, between cultivation made with and without selenium.

\section{Material and methods}

\subsection{Materials}

Sugar beet molasses, as substrate, was provided from Sahand Company (Khoy, Iran). It has ${ }^{\circ}$ Brix, total reduced sugar amount, $\mathrm{pH}$, ash content and density values of 74.07 $\left({ }^{\circ} \mathrm{Bx}\right), 48.65 \%, 6.16,9.6(\% \mathrm{v} / \mathrm{v})$ and $1.385 \times 10^{3}\left(\mathrm{~kg} / \mathrm{m}^{3}\right)$, respectively. Commercial $S$. cerevisiae strain, SFO6, was obtained from Iran Mayeh Company (Tehran, Iran). 30\% v/v sulfuric acid (as $\mathrm{pH}$ adjuster), Diammonium hydrogen phosphate (as phosphorus source) and urea (as nitrogen supplement) were purchased from the Dr. Mojallali Company (Tehran, Iran). Sodium selenite $\left(\mathrm{Na}_{2} \mathrm{SeO}_{3}\right)$ with purity of higher than 99\% (as selenium precursor) was provided from Merck Company (Merck Co., Darmstadt, Germany).

\subsection{Inoculum preparation through aerobic process}

Provided molasses was sterilized using a laboratory autoclave (RT-1, Reyhan Teb, Tehran, Iran), adjusted at temperature of $121^{\circ} \mathrm{C}$ and pressure of 1.5 bar for $15 \mathrm{~min}$, diluted using sterilized distilled water to prepared aqueous molasses with brix value of $11\left({ }^{\circ} \mathrm{Bx}\right)$ using a refractometer (Index instrument Ltd., Kissimmee, FL, USA), enriched with $250 \mathrm{mg} / \mathrm{L}$ urea and $500 \mathrm{mg} / \mathrm{L}$ urea and diamonium hidrogen phosphate, and adjusted its $\mathrm{pH}$ to 4.2. After that, prepared substrate containing $0.3 \mathrm{~g} / \mathrm{L}$ provided industrial yeast, was aerated using shaker incubator (S1-300, Jeio Tech, Daejeon, Korea,) $120 \mathrm{rpm}, 1$ (VVM) at $32^{\circ} \mathrm{C}$ for $24 \mathrm{~h}$.

\subsection{Growth of S. cerevisiae in the prepared molasses}

Optical density measurement was used to monitore the growth of $S$. cerevisiae in the provided molasses with ${ }^{\circ} \mathrm{Bx}$ of 11 , as mentioned in inoculum preparation through aerobic process. In order to evaluate of the effect of selenium amounts $(0,5,10,15,20$ and $25 \mu \mathrm{g})$ on the growth of the $S$. cerevisiae, after preparation of molasses containing $0.3 \mathrm{~g} / \mathrm{L}$ of the yeast, defined amounts of selenium were added into that and the absorbance of the prepared samples, as an optical density, was measured every $1 \mathrm{~h}$, using UV-Vis spectrophotometry (Jenway UV-Vis spectrophotometer 6705 , Staffordshire, UK) adjusted at wavelength of $625 \mathrm{~nm}$ $[5,6]$. For this reason, samples were diluted 4 times with distilled water to decrease their colour intensity and after that, those were subjected to the spectrophotometer. The recorded values were then multiplied in 4 to obtain exact value of optical density for the samples.

\subsection{Bioethanol production through anaerobic submerged fermentation and its concentration measurment}

Bioethanol was produced using anaerobic batch submerged fermentation when, $60 \mathrm{~mL}$ of the prepared 
inoculum with $11^{\circ} \mathrm{Bx}$ and different amount of sodium selenite $(5-25 \mu \mathrm{g})$ were added into the $140 \mathrm{~mL}$ of the diluted and sterilized molasses with different brix value ranging 10 to $25^{\circ} \mathrm{Bx}$. The mixture solutions were then filled into the $250 \mathrm{~mL}$ rubber sealed glass jars and incubated (at $32^{\circ} \mathrm{C}$ for $32 \mathrm{~h}$ ). Finaly, the concentration of the produced bioethanol was calculated using technique based on distillation. In this manner, after bioethanol distillation and true brix measurement in distilled fermentation broth by a refractometer (Index instrument Ltd., Kissimmee, FL, USA), bioethanol concentration was measured using a hydrometer [5].

\subsection{Experimental design and statistical analysis}

According to the literature studies, two independent variables namely, amount of sodium selenite $\left(\mu \mathrm{g}, \mathrm{X}_{1}\right)$ and substrate brix $\left({ }^{\circ} \mathrm{Bx}, \mathrm{X}_{2}\right)$ were selected to evaluate their effects on bioethanol concentration ( $\mathrm{g} / \mathrm{L}, \mathrm{Y})$, as response variable, using response surface methodology (RSM) $[6,8,9,14]$. Central composite design (CCD) was utilized to design of experiments, including 13 experiment runs (Table 1), based on axial point system and 1 block [17,18]. In order to model the bioethanol concentration $(\mathrm{g} / \mathrm{L}$, $\mathrm{Y})$ as function of two selected independent variables, a second order polynomial equation was selected $[19,20]$. Suitability of the generated model was studied based on the coefficient of determination $\left(\mathrm{R}^{2}\right)$ and lack-of-fit $\mathrm{p}$-value $[21,22]$. In order to significance determination of the resulted model, analysis of variance (ANOVA) was used based on $p$-value term $(p<0.05)$ [23,24]. Minitab software (v.16 statistical package, Minitab Inc., PA, USA) was used to design of experiments and statistical analysis.

\subsection{Optimization of the bioethanol fermentation conditions}

To find optimum area with in defined ranges for the fermentation variables, contour plot was establish [25]. Furthermore, to obtain the exact values of the optimized fermentation conditions which in that bioethanol with highest concentration were produced, numerical optimization was used [6]. Three additional approval tests were performed at obtained optimum conditions to verify the validity of the statistical experimental method [26]. For this reason, Tukey's comparison test was performed between the values of the predicted and experimental
Table 1: Central composite design (CCD) for the bioethanol production using S. cerevisiae.

\begin{tabular}{|c|c|c|c|c|c|}
\hline & $\begin{array}{l}\text { Selenium } \\
\text { amount }(\mu g)\end{array}$ & $\begin{array}{l}\text { Substrate } \\
\text { brix }\left({ }^{\circ} \mathrm{Bx}\right)\end{array}$ & $\begin{array}{l}\text { Experimental } \\
\text { bioethanol concen- } \\
\text { tration }(\mathrm{g} / \mathrm{L})\end{array}$ & $\begin{array}{l}\text { Predicted } \\
\text { n- bioethanol con } \\
\text { tration }(\mathrm{g} / \mathrm{L})\end{array}$ & oncen- \\
\hline 1 & 15 & 10 & 15 & 5 & 15.04 \\
\hline 2 & 15 & 25 & 55 & 5 & 55.20 \\
\hline 3 & 5 & 17.5 & 27 & 7 & 27.38 \\
\hline 4 & 8 & 12.2 & 17 & 7 & 16.74 \\
\hline 5 & 15 & 17.5 & 29 & 9 & 29.00 \\
\hline 6 & 15 & 17.5 & 29 & 9 & 29.00 \\
\hline 7 & 15 & 17.5 & 29 & 9 & 29.00 \\
\hline 8 & 25 & 17.5 & 33 & 3 & 32.86 \\
\hline 9 & 22 & 22.8 & & * & * \\
\hline 10 & 8 & 22.8 & 45 & 5 & 44.63 \\
\hline 11 & 15 & 17.5 & 29 & 9 & 29.00 \\
\hline 12 & 15 & 17.5 & 29 & 9 & 29.00 \\
\hline 13 & 22 & 12.2 & 20 & 0 & 20.11 \\
\hline
\end{tabular}

* Out of range

bioethanol concentration at obtained optimum fermentation conditions. Minitab software (v.16 statistical package, Minitab Inc., PA, USA) was used to optimization and validation procedures.

\section{Results and discussion}

\subsection{Effects of selenium on the growth of S. cerevisiae}

Effects of different amounts of selenium on the growth (manifested as turbidity intensity) of $S$. cerevisiae, show in Figure 1. As clearly observed in this figure, the growth of the yeast in the provided molasses without selenium was significantly $(\mathrm{p}<0.05)$ higher than that of those which were included with different amounts of selenium. According to the Figure 1, the slope of each curve, as growth rate, was calculated from beginning of the experiments up to $14 \mathrm{~h}$ after incubation. The obtained results indicated that growth rate (manifested as turbidity intensity (\% a.u.)) of the $S$. cerevisiae in the samples including, 0,5 , 10, 15, 20 and $25 \mu$ s selenium was $0.1707,0.1678,0.1679$, $0.1664,0.1627$ and $0.160 \%$ a.u./h, respectively. Tukey's comparison test was indicated that there was insignificant ( $p>0.05$ ) differences between growth rate (manifested as turbidity intensity) of the $S$. cerevisiae in the samples containing $S$. cerevisiae and 5 to $25 \mu \mathrm{g}$ selenium. It can 


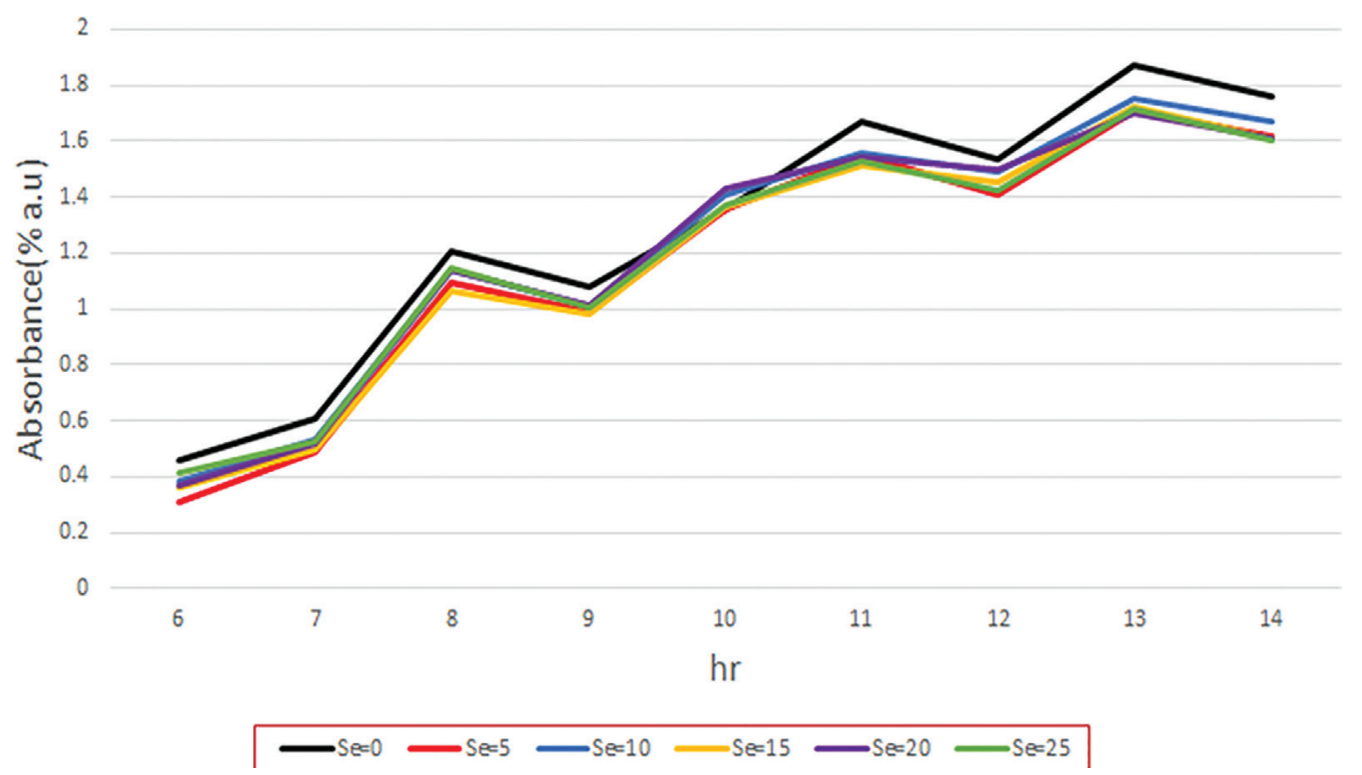

Figure 1 Effects of different amounts of selenium on the growth of S. cerevisiae.

be related to the lower bioavailability of the organic selenium in S. cerevisiae [16]. The obtained result was also in agreement with findings of Hamza et al. [15]. They also found that some species of Saccharomyces, had selenium tolerance and selenium in lower amounts, could not be significantly inhibit its growth.

\subsection{Effects of substrate brix and selenium amount on the concentration of produced bioethanol}

According to the experiment runs and obtained values for the concentration of produced bioethanol through submerged fermentation (Table 1), the second order model fitted to correlate bioethanol concentration to the fermentation parameters, namely selenium amount and inoculum brix. Estimated regression coefficients and $\mathrm{P}$-values of the main, quadratic and interaction terms of the generated polynomial model are presented in Table 2 . As clearly observed in Table 2, the main term of the selenium amount and its interaction with medium brix had insignificant $(p>0.05)$ effects on the concentration of bioethanol. But, the main term of medium brix and quadratic terms of both selected fermentation parameters had significant $(\mathrm{p}<>0.05)$ effects on the produced bioethanol concentration. It means that with in the defined ranges for the independent variables, concentration of the produced bioethanol affected by lower and higher brix of the medium, and only higher amounts of selenium salt. Statistical analysis had also shown high values
Table 2: $\quad P$ values and regression coefficients for the generated model using $S$. cerevisiae.

\begin{tabular}{|c|c|c|c|c|}
\hline \multicolumn{3}{|c|}{ P-value } & \multicolumn{2}{|c|}{ Regression coefficient } \\
\hline Parameters & $\begin{array}{r}\text { Independent } \\
\text { variables }\end{array}$ & P-value & $\beta$ & Coefficient \\
\hline Constant & & 0.000 & $\begin{array}{r}\beta_{0} \\
\text { (Constant) }\end{array}$ & 15.71 \\
\hline \multirow[t]{2}{*}{ Main term } & $\mathrm{X}_{1}$ & 0.135 & $\beta_{1}$ & -0.18 \\
\hline & $\mathrm{X}_{2}$ & 0.000 & $\beta_{2}$ & -1.23 \\
\hline \multirow{2}{*}{$\begin{array}{l}\text { Quadratic } \\
\text { term }\end{array}$} & $\mathrm{X}^{2}{ }_{1}$ & 0.002 & $\beta_{11}$ & 0.01 \\
\hline & $\mathrm{X}^{2}{ }_{2}$ & 0.000 & $\beta_{22}$ & 0.1 \\
\hline $\begin{array}{l}\text { Interaction } \\
\text { term }\end{array}$ & $\mathrm{X}_{1} \mathrm{X}_{2}$ & 0.189 & $\beta_{12}$ & 0.00 \\
\hline $\mathrm{R}^{2}$ & & 0.9997 & & \\
\hline $\begin{array}{l}\text { Lack-of-fit } \\
\text { (p-value) }\end{array}$ & & 0.420 & & \\
\hline
\end{tabular}

1: Amount of selenium $(\mu \mathrm{g})$

2: Substrate brix $\left({ }^{\circ} \mathrm{Bx}\right)$

for the $\mathrm{R}^{2}(0.9997)$ and lack-of-fit (p-value of 0.420 ) of the generated model which those indicated suitability and accuracy of the resulted model for predicting of bioethanol concentration with in the defined ranges for the fermentation parameters [19,22].

As can be seen in Table 1, the concentration of the produced bioethanol was varied from 15 to $55 \mathrm{~g} / \mathrm{L}$. Figure 2, indicates the effects of selenium amount and substrate brix on the concentration of produced bioethanol. As can be seen in Figure 2, at any constant 


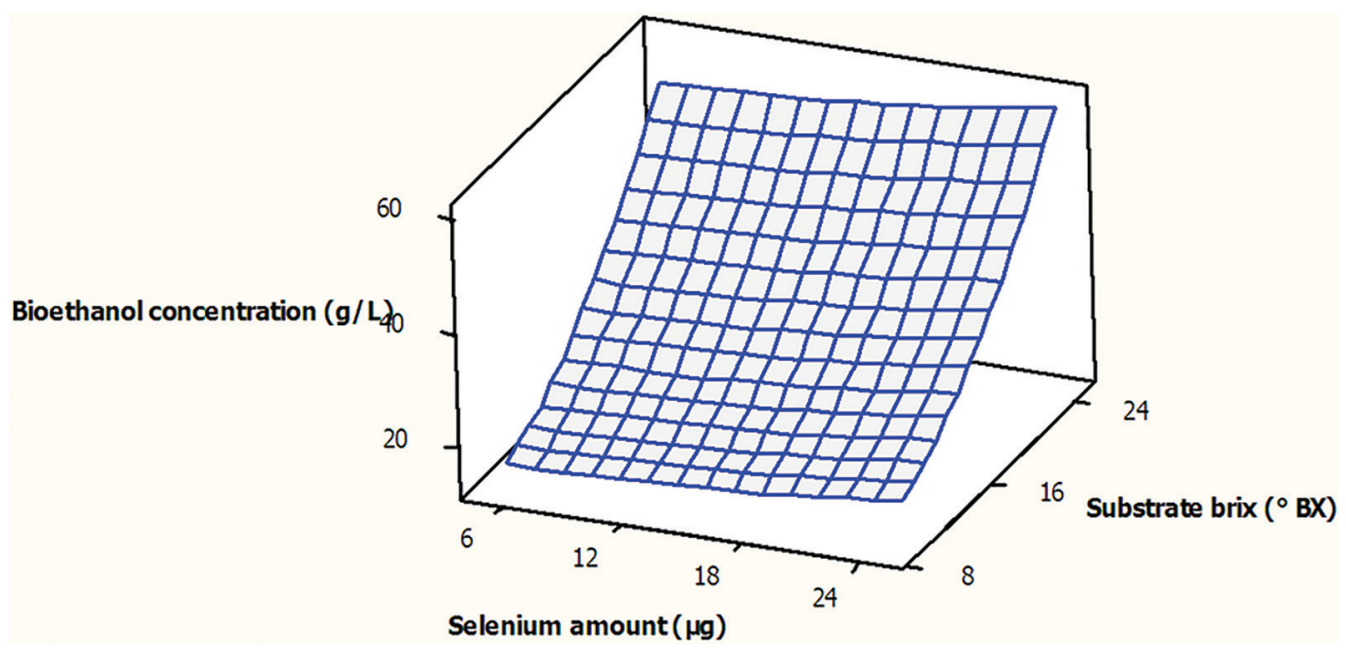

Figure 2: Surface plot for concentration of the produced bioethanol $(\mathrm{g} / \mathrm{L})$ as function of the substrate brix $\left({ }^{\circ} \mathrm{Bx}\right)$ and amount of selenium $(\mu \mathrm{g})$, during submerged fermentation.

amount of selenium, by increasing the brix of substrate, bioethanol concentration, increased. This result was in agreement with finding of Shaghaghi-Moghadam et al. [6]. They indicated by increasing the substrate brix, the concentration of the fermentable sugar increased which in turn, increased the concentration of the produced bioethanol. One of the factors which can highly affect the fermentation performance is the medium osmotic pressure which that increases by increasing the medium brix and may negatively affect the yeast growth and bioethanol production [6]. As same as this pattern, at any constant substrate brix, by increasing the amount of selenium, the concentration of the produced bioethanol was increased. However, the effect of substrate brix on the increasing of the bioethanol was higher than the selenium amount, due to its lower p-value (0.000). The presence of no curvature in the Figure 2 also demonstrated that the interaction between substrate brix and amount of selenium did not has significant $(p<0.05)$ effect on bioethanol concentration. Obtained result was reconfirmed by achieved high $\mathrm{p}$-value ( $p>0.05)$ of the interaction term (0.189) as can be observed clearly in Table 2 .

\subsection{Optimization of the fermentation process}

In order to achieve bioethanol with highest concentration through submerged fermentation, the obtained numerical optimization result revealed that fermentation using $15 \mu \mathrm{g}$ sodium selenite and substrate with $25^{\circ} \mathrm{Bx}$ attained to produce bioethanol with highest concentration value of $55.2 \mathrm{~g} / \mathrm{L}$. Graphical optimization shows in Figure 3. As can



Figure 3: Graphical optimization plot for concentration of the produced bioethanol $(\mathrm{g} / \mathrm{L})$ as function of the substrate brix $\left({ }^{\circ} \mathrm{Bx}\right)$ and amount of selenium $(\mu \mathrm{g})$, during submerged fermentation.

be seen in this figure, at any constant substrate brix value, for lower amount of selenium, by increasing the amount of selenium, the concentration of produced bioethanol was constant and at higher amounts of selenium, increasing its amount had significant ( $p<0.05$ ) effect on the concentration of bioethanol. This result was reconfirmed by the obtained statistical data for the insignificant effect of lower amounts of selenium ( $p$-value $=0.135$ ) on the concentration produced bioethanol (Table 2). Graphical optimization plot was illustrated that, with in the defined ranges for the independent variables, maximum bioethanol was achieved using highest substrate brix values. Experimental data for the obtained bioethanol concentration $(55 \pm 2 \mathrm{~g} / \mathrm{L})$ using the optimum fermentation parameters revealed that there was insignificant $(p>0.05)$ 
difference between the values of the experimental and predicted concentration of produced bioethanol and indicated the adequacy of the fitted model.

In this work, selenium was applied in a submerged fermentation to study its effects on production of bioethanol. For this reason, an anaerobic fermentation process was run at same conditions as obtained optimum conditions without selenium. In fact, at this fermentation process, the substrate brix was chosen at $25^{\circ} \mathrm{Bx}$ and the amount of sodium selenite was zero. Obtained result indicated that the concentration of produced bioethanol was $29 \mathrm{~g} / \mathrm{L}$ which was $52.3 \%$ lower than that of obtained using $15 \mu \mathrm{g}$ selenium $(55 \pm 2 \mathrm{~g} / \mathrm{L})$. Obtained result can be explained by the fact that existed glutamate in the yeast, negatively impacts the mitochondria by altering the mitochondrial structure and dysregulation of mitochondria dynamics which is decreased the energy generation and fermentation rate. S. cerevisiae by converting inorganic selenium to selenocysteine, utilized this seleno-amino acid to prevent glutamate-induced effect [27]. It seems that $S$. cerevisiae has high potential to bio-transform selenium to organic selenium compounds such as seleno-proteins which was confirmed by findings of Pérez-Corona et al. [14] and Porto et al. [12].

\section{Conclusions}

Present study indicated that production of bioethanol with high concentration, through submerged fermentation process, could be resulted by increasing the concentration of molasses (substrate) and utilizing high amounts of selenium, as regulator of the yeast mitochondria dynamics function. The obtained results indicated that lower amounts of selenium had insignificant effect on the concentration of the produced bioethanol. Results also revealed that the selected industrial S. cerevisiae strain had high resistance against osmotic pressure of the fermented broth which it makes possible to achieve bioethanol with twice concentration when comparison was made between cultivation made with and without selenium using highest substrate brix. Finally, RSM could be successfully used to generate model, optimize the process and predict the bioethanol concentration with in the defined ranges for the selenium amount and substrate brix.

Acknowledgment: The authors would like to appreciate the Bidestan Company (Qazvin, Iran) for the analysis and material supports.
Conflicts of interest: All authors declare no conflict of interest.

\section{References}

[1] Jafari N., Jafarizadeh-Malmiri H., Hamzeh-Mivehroud M., Adibpour M., Optimization of UV irradiation mutation conditions for cellulase production by mutant fungal strains of Aspergillus niger through solid state fermentation. Green Process. Synth., 2017, 6, 333-340.

[2] Hill J., Nelson E., Tilman D., Polasky S., Tiffany D., Environmental, economic, and energetic costs and benefits of biodiesel and ethanol biofuels. Proc. Nat. Acad. Sci., 2006, 103, 11206-11210.

[3] Ko J.K., Lee S.M., Advances in cellulosic conversion to fuels: engineering yeasts for cellulosic bioethanol and biodiesel production. Curr. Opin. Biotechnol., 2018, 50, 72-80.

[4] Mohd Azhar S.H., Abdulla R., Jambo S.A., Marbawi H., Gansau J.A., Mohd Faik A.A., et al., Yeasts in sustainable bioethanol production: A review. Biochem. Biophys. Rep., 2017, 10, 52-61.

[5] Shaghaghi-Moghadam R., Jafarizadeh-Malmiri H., Mehdikhani P., Jalalian S., Alijanianzadeh R., Screening of the five different wild, traditional and industrial Saccharomyces cerevisiae strains to overproduce bioethanol in the batch submerged fermentation. Z. Naturforsch., 2018, 73, 361-366.

[6] Shaghaghi-Moghadam R., Jafarizadeh-Malmiri H., Mehdikhani P., Alijanianzadeh R., Jalalian S., Optimization of submerged fermentation conditions to overproduce bioethanol using two industrial and traditional Saccharomyces cerevisiae strains. Green Process. Synth., 2019, 8, 157-162.

[7] Izquierdo A., Casas C., Herrero E., Selenite-induced cell death in Saccharomyces cerevisiae: protective role of glutaredoxins. Microbiol., 2010, 156, 2608-2620.

[8] Oraby M.M., Allababidy T., Ramadan E.M., The bioavailability of selenium in Saccharomyces cerevisiae. Ann. Agric. Sci., 2015, 60, 307-315.

[9] Ponce de Leon C.A., Bayon M.M., Paquin C., Caruso J.A., Selenium incorporation into Saccharomyces cerevisiae cells: a study of different incorporation methods. J. Appl. Microbiol., 2002, 92, 602-610.

[10] Bronzetti G., Cini M., Andreoli E., Caltavuturo L., Panunzio M., Croce C.D., Protective effects of vitamins and selenium compounds in yeast. Mutat. Res., 2001, 496, 105-115.

[11] Fagan S., Owens R., Ward P., Connolly C., Doyel S., Murphy R., Biochemical comparison of commercial selenium yeast preparations. Biol. Trace Elem. Res., 2015, 166, 245-259.

[12] Porto B.A.A., Mangiapane E., Pessione A., Neves M.J., Pessione E., Martins F., Evaluation of sodium selenite effects on the potential probiotic Saccharomyces cerevisiae UFMG A-905: A 
physiological and proteomic analysis. J. Funct. Foods, 2015, 17, 828-836.

[13] Jiménez-Lamana J., Abed-Alvaro I., Bierla K., Laborda F., Szpunar J., Lobinski R., Detection and characterization of biogenic selenium nanoparticles in selenium-rich yeast by single particle ICPMS. J. Anal. At. Spectrom., 2018, 33, 452-460.

[14] Pérez-Corona M.T., Sánchez-Martínez M., Valderrama M.J., Rodríguez M.E., Cámara C., MadridY., Selenium biotransformation by Saccharomyces cerevisiae and Saccharomyces bayanus during white wine manufacture: laboratory-scale experiments. Food Chem., 2011, 124, 1050-1055.

[15] Hamza F., Vaidya A., Apte M., Kumar A.R., Zinjarde S., Selenium nanoparticle-enriched biomass of Yarrowia lipolytica enhances growth and survival of Artemia salina. Enzyme Microb. Technol., 2017, 106, 48-56.

[16] Oraby M.M., Allababidy T., Ramadan E.M., The bioavailability of selenium in Saccharomyces cerevisiae. Ann. Agric. Sci., 2015, 60, 307-315.

[17] Amirkhani L., Moghaddas J., Jafarizadeh-Malmiri H., Candida rugosa lipase immobilization on magnetic silica aerogel nanodispersion. RSC Adv., 2016, 6, 12676-12687.

[18] Eskandari-Nojedehi M., Jafarizadeh-Malmiri H., RahbarShahrouzi J., Hydrothermal green synthesis of gold nanoparticles using mushroom (Agaricus bisporus) extract: physico-chemical characteristics and antifungal activity studies. Green Process. Synth., 2018, 7, 38-47.

[19] Ahdno H., Jafarizadeh-Malmiri H., Development of a sequenced enzymatically pre-treatment and filter pre-coating process to clarify date syrup. Food Bioprod. Process., 2017, 101, 193-204.

[20] Mohammadlou M., Jafarizadeh-Malmiri H., Maghsoudi H., Hydrothermal green synthesis of silver nanoparticles using Pelargonium/Geranium leaf extract and evaluation of their antifungal activity. Green Process. Synth., 2017, 6, 31-42.
[21] Ahmadi O., Jafarizadeh-Malmiri H., Jodeiri N., Eco-friendly microwave-enhanced green synthesis of silver nanoparticles using Aloe vera leaf extract and their physico-chemical and antibacterial studies. Green Process. Synth., 2018, 7, 231-140.

[22] Ghanbari S., Vaghari H., Sayyar Z., Adibpour M., JafarizadehMalmiri H., Autoclave-assisted green synthesis of silver nanoparticles using $A$. fumigatus mycelia extract and the evaluation of their physico-chemical properties and antibacterial activity. Green Process. Synth., 2018, 7, 217-224.

[23] Eskandari-Nojedehi M., Jafarizadeh-Malmiri H., Jafarizad A., Microwave accelerated green synthesis of gold nanoparticles using gum Arabic and their physico-chemical properties assessments. Z. Phys. Chem., 2018, 232, 325-343.

[24] Nottagh S., Hesari J., Peighambardoust S.H., Rezaei-Mokarram R., Jafarizadeh-Malmiri H., Development of a biodegradable coating formulation based on the biological characteristics of the Iranian Ultra-filtrated cheese. Biologia, 2018, 73, 403-410.

[25] Anarjan N., Jaberi N., Yeganeh-Zare S., Banafshehchin E., Rahimirad A., Jafarizadeh- Malmiri H., Optimization of mixing parameters for $\alpha$-Tocopherol nanodispersions prepared using solvent displacement method. J. Am. Oil Chem. Soc., 2014, 91, 1397-1405.

[26] Jafarizadeh-Malmiri H., Osman A., Tan C.P., Abdul Rahman R., Effects of edible surface coatings (sodium carboxymethyl cellulose, sodium caseinate and glycerol) on storage quality of berangan banana (Musa sapientum cv. Berangan) using response surface methodology. J. Food Process. Preserv., 2012, 36, 252-261.

[27] Ma M.Y., Guo Y.Z., Ibeanu G., Wang L.Y., Dong J.D., Wang J., et al., Overexpression of selenoprotein $\mathrm{H}$ prevents mitochondrial dynamic imbalance induced by glutamate exposure. Int. J. Biol. Sci., 2017, 13, 1458-1469. 